\title{
Fluorescence diagnosis and flat lesions of urothelium: New challenges for pathologists and urologists (Review)
}

\author{
EVA COMPÉRAT ${ }^{1}$, PIERRE CONORT $^{2}$, MORGAN ROUPRET $^{2}$, FRÉDERIQUE CAPRON $^{1}$, \\ PHILIPPE CAMPARO 3 and RODOLFO MONTIRONI ${ }^{4}$
}

\author{
${ }^{1}$ Service d'Anatomie Pathologique, ${ }^{2}$ Service d'Urologie, Hôpital La Pitié Salpètriere, AP-HP, Université Pierre et Marie Curie, \\ Paris VI; ${ }^{3}$ Service d'Anatomie Pathologique, Hôpital d'Instruction des Armées Val-de-Grâce, Paris, France; \\ ${ }^{4}$ Institute of Pathological Anatomy and Histopathology Polytechnic University of the Marche Region, Ancona, Italy
}

Received September 19, 2008; Accepted November 5, 2008

DOI: 10.3892/or_00000292

\begin{abstract}
Bladder cancer is a common malignancy. Recurrence rate and progression vary greatly depending on factors such as tumor multiplicity, size, previous recurrence rates, tumor stage, tumor grade and the presence of carcinoma in situ. Treatment is expensive, recent studies demonstrated that superficial bladder cancer is a major economic burden. It is necessary to establish new kinds of techniques to improve diagnosis, therapy and follow-up, such as fluorescence diagnosis, without adding significant risk of complications. As urologists have a better sight of bladder lesions with fluorescence diagnosis, pathologists will be asked in the future to evaluate more frequently flat lesions, which up to now would not have been a matter of concern. For several reasons it is very important to have accurate and precise definitions of these flat lesions. First to permit uniform treatment of large groups of patients and second to see in large cohorts the evolution and natural history of several flat lesions, not always well known up to now. The aim of the study was to review the most important flat lesions, to demonstrate the difficulty of classifying several lesions, to introduce to urologists the new problems linked to FD and to suggest new models for accurate analysis. How far can we go in our answer as pathologists and how will it change the patient management?
\end{abstract}

\section{Contents}

1. Introduction

2. Normal urothelium

3. Metaplasia

Correspondence to: Dr Eva Compérat, Service d'Anatomie Pathologique, Hôpital La Pitié Salpètriere, AP-HP, Université Pierre et Marie Curie, Paris VI, France

E-mail: eva.comperat@psl.aphp.fr; evacomperat@yahoo.fr

Key words: fluorescence diagnosis, hexvix, flat lesions, bladder, bladder cancer, detection, treatment, follow-up
4. Flat lesions without atypia

5. Flat lesions with atypia

6. Dysplastic lesions

7. Therapy associated atypia

8. Aspects of fluorodetection in bladder examination

9. Discussion

10. Conclusion

\section{Introduction}

Bladder cancer is the 4th most common malignancy among men in the Western world. Recurrence rate and progression vary greatly depending on factors such as tumor multiplicity, size, previous recurrence rates, tumor stage, tumor grade and the presence of carcinoma in situ (Cis) (1). Especially in case of superficial cancer, which concerns $75-85 \%$ of bladder cancer patients, treatment is very expensive. Recent studies demonstrated that superficial bladder cancer is a major economic burden (2). These findings illustrate the economic and medical necessity to establish new kinds of techniques to improve diagnosis, therapy and follow-up (3). Fluorescence diagnosis (FD) with 5 aminolevulinic acid (5ALA) has been shown to improve the detection of flat bladder lesions, especially Cis without adding significant risk of complications (4).

Before FD pathologists and urologists focused on Cis and pTa-pT2 tumors on biopsy or resection. As urologists have a better sight of bladder lesions with FD, pathologists will be asked in the future to evaluate more frequently flat lesions, which up to now would not have been a matter of concern. For several reasons it is very important to have accurate and precise definitions of these flat lesions. First to permit uniform treatment of large groups of patients and second to see in large cohorts the evolution and natural history of several flat lesions, not always well known up to now.

The aim of the study was to review the most important flat lesions, to demonstrate the difficulty of classifying several lesions, to sensitize urologists to the new problems linked to FD and to suggest new models for accurate analysis. We evaluated how far pathologists can go and how this will change the patient management. 
The WHO 2003 has considered several lesions as flat intraurothelial lesions (see Table I). Histological parameters to classify the following lesions are as described in Table II.

We describe the major lesions and the lesions difficult to classify and give detailed aspects of the Hexvix examination with the corresponding diagnosis.

\section{Normal urothelium}

Normal urothelium is composed of three different layers. The most superficial layer is covered by umbrella cells. These might display atypical aspects either in singular cells or in lager sectors. Mild degrees of variation in architecture without cytological atypia can be admitted in urothelium, there are usually no mitosis.

\section{Metaplasia}

Several types of metaplasia exist and must not be misdiagnosed.

Squamous metaplasia. The most frequent is squamous metaplasia (SqM), which is common if the area is not extensive, very inflammatory or keratinizing. Parakeratosis, hyperkeratosis and even granular layers might exist in our experience. Nevertheless SqM has been considered as a precancerous lesion by some authors. Guo et al showed in a recent study increasing numbers of squamous cell carcinomas after detection of SqM, but the number of cases was restricted (5). Enhanced expression of EGFR in these bladder squamous lesions suggests that EGFR may represent a therapeutic target. Wide-range human papillomavirus DNA signal was occasionally detected (5).

Glandular metaplasia (GM). GM might be seen in the surface of urothelium, as a response to chronic irritation or inflammation, such as neurogenic overactive bladder, bladder extrophy, long-term catheterization or history of calculi. There are still discordant data on the value of GM as a precancerous lesion. Recent data confirm that intestinal metaplasia and cystitis glandularis involve divergent pathways (6). Telomere shortening and analysis of chromosomal abnormalities support the hypothesis of intestinal metaplasia as a precursor lesion and could be a marker in the development of adenocarcinoma of the urinary bladder (7).

Nephrogenic metaplasia (NM). NM is also common with male predominance. It is seen in bladder walls with history of injuries. NM might mimic polypoid hyperplastic lesions, sometimes it is velvet-like. It might be tricky in case of inflammatory sub-mucosa with endothelial or hobnail aspects. These features might be difficult to distinguish from Cis or low grade dysplasia and not experienced pathologist might misinterpret NM as an adenocarcinoma or metastasis of an adenocarcinoma. NM is totally benign and has to be recognized to avoid overtreatment. Recent evidence has demonstrated that nephrogenic adenoma is a true 'nephrogenic' lesion derived from the exfoliated and implanted renal tubular cells in the urinary tract $(8,9)$.
Table I. Flat intraurothelial lesions.

\section{Normal}

Hyperplasia

Flat lesions with atypia

Reactive inflammatory type

Dysplasia low-grade intraurothelila lesions

Carcinoma in situ (high grade intraurothelial lesions)

Atypia of unknown significance

Table II. Histological parameters.

Thickness of urothelial epithelium

Cellular polarity

Aspects of cytoplasm, especially if clear cytoplasm

Nuclear size, crowding, borders, aspects of chromatin

Presence of nuclei

Mitosis especially if atypical forms

Association with inflammation

Increasing density of small vessels under the lamina propria

\section{Flat lesions without atypia}

Flat urothelial hyperplasia (FUH). In this kind of settings urothelium is thickened ( $>7$ layers), but lacks cytologic atypia, some degree of nuclear enlargement can be observed. FUH might surround low grade pTa tumors. FUH was mostly seen in cases of follow-up of pTa tumors and generally considered as a minor finding. Several studies could demonstrate genetic abnormalities already present in hyperplasia such as loss of heterozygosity of FGFR-3 gene and deletion of chromosome 9 in $70 \%$ of FUH (10-12). This raises the question of whether FUH should be considered as detection of an early premalignant urothelium lesion with low-risk profile (13).

\section{Flat lesions with atypia}

Reactive atypia (RA). RA is sometimes difficult to classify and not perfectly standardized in classifications. The inflammatory context usually helps to determine the lesions, which might be various. Increasing size of nuclei, with a globally preserved architecture and increasing cellular density are common. Increasing vascularisation has been described in the submucosa $(14,15)$. Several cases of RA with mitosis have been described. Mitosis are in the lower layers of urothelium and never atypical (15). A pitfall might be denuded areas or atrophy of urothelium. Contrary to Cis, no increasing ratio between nucleus and cytoplasm, no hyperchromatic nuclei and no membrane irregularity are observed (16). In case of suspicion of RA, clinical history such as history of previous biopsies is very important to avoid overgrading of lesions (17). 
Urothelial atypia with unknown significance. This entity is not very well defined and one should avoid using the term in case of diagnostic difficulties. Usually, inflammatory features are observed, and Cis or dysplasia cannot be totally excluded. Lopez-Beltran discouraged the use of this term, without any value in practice (12). If the pathologist is unable to decide between reactive, dysplastic or Cis, the term can be used. Urologists must be aware that this entity needs antiinflammatory treatment and new biopsies to make a final diagnosis.

\section{Dysplastic lesions}

Low grade urothelial dysplasia (LGUD). LGUD is one of the major problems if isolated. LGUD is characterized by nuclear and architectural abnormalities with normal thickness of urothelium $(14,18)$. LGUD is commonly seen in patients with bladder neoplasia. In patients without urothelial neoplasia the risk of developing cancer has been estimated to only $19 \%$ in an 8-year mean follow-up when LUGD are present, while observed from 32 to $83 \%$ of patients when associated to Cis $(19,20)$. One possible explanation is the coexistence of two main molecular pathways of bladder tumor progression involving p53 (from flat dysplasia to Cis) or loss of heterozygosity on chromosome 9 (from dysplasia to low-grade papillary carcinoma but no Cis), with common interactions and overlapping (19).

Two main differential diagnoses remain: RA and Cis. Immunohistochemistry might be helpful. Aberrant CK20 expression in basal urothelial cells plus overexpression of p53 and Ki-67 and loss of CD44 expression might be helpful (21-23). Several studies have demonstrated increasing incidence if associated with Cis or papillary carcinoma, but we lack recent studies concerning prognosis of isolated lesions $(1,24)$. One reason for the lack of data might be the problem of reproducibility in grading dysplasia $(12,13,25,26)$.

Urothelial carcinoma in situ (Cis)/involvement of von Bruns nests/microinvasion/extensive denudation. Diagnosis of Cis is not common, features are well defined and pathologists are used to handling Cis. Frequently denuded urothelium exists underlining the discohesive nature of tumor cells. Owens and Epstein showed in a recent study that the majority of denuded lesions were of high grade. In case of important denudation urinary cytology might be helpful to determine diagnosis (27). Nevertheless, pathologists should be careful especially in case of cautery artefacts or in anatomically confined areas (28). Several different histological patterns exist, but it is probably not important to subclassify Cis in the pathology report, because different patterns do not seem to make any difference in clinical follow-up (21) (for patterns see Table III).

Differential diagnosis might be difficult with RA if cells display few atypia. Clinical history of radiotherapy has to be mentioned by urologists; otherwise reactive changing linked to the treatment might be misinterpreted.

Immunohistochemistry might be helpful to distinguish Cis from RA. In our experience a panel of p53, MIB-1 and Aurora-A, implied in early mitosis, is overexpressed in Cis, but to a lesser extent in RA (29). p53 and MIB-1 usually
Table III. Different histologic patterns in urothelial carcinoma in situ.

Large cell Cis

Pleomorphic

Non-pleomorphic

Small cell

Clinging

Pagetoid

Undermining/overriding

display strong nuclear staining in Cis. Aurora-A is overexpressed in the cytoplasm and perinuclear in Cis, it has also been shown that overexpression of these 3 markers predicts relapse (30). One should also think of Cis extending to von Brunn Nests, or exclusively being present in the latter. This aspect must not be mistaken for microinvasion.

\section{Therapy associated atypia}

Truncated papillae. This kind of lesions is not well known by many pathologists and can be observed after Mitomycin-C therapy. The top of the papillae is destroyed by chemotherapy. Together with inflammation and denudation truncated papillae might be mistaken as Cis $(16,27)$.

Treated papillary carcinoma/granulomas. After BCG therapy granulomas containing epitheliod histocytes and multinucleated giant cells are common. When sending biopsies or resection material after treatment, it is important to have clinical history of the patient, otherwise differential diagnosis with urogential tuberculosis might be difficult. Ziehl-Nielsen staining is usually negative (16).

Radiation. Indication of radiation is rare nowadays, but microscopic changes might be very impressive and misleading. These lesions might be indistinguishable from $\mathrm{C}$ is if no clinical history is known, they might persist for years after therapy (31).

\section{Aspects of fluorodetection in bladder examination}

A new ester of 5ALA (Hexvix $\left.{ }^{\circledR}\right)$ has already shown its potential in FD with a short time of instillation $(1 \mathrm{~h})$ before cystoscopy.

Normal urothelium does not emit any fluorescent signal in FD examination. The three types of metaplasia have different aspects which are characteristic in each case. SqM might be just present in white light examination as a brown plaque, but does not always display fluorescent signals. There seems to be a correlation between thickness of SqM and light signals. GM might show luminous signals which are pink and most of the time not very intense. NM is clearly seen by the urologist during FD examination, the velvet-like, crete-like aspect is preserved and typical (Fig. 1).

During FD examination FUH displays generally only slightly luminous signals. FUH represented $14.4 \%$ of the false positive biopsy findings in a large series of FD (13). 
A

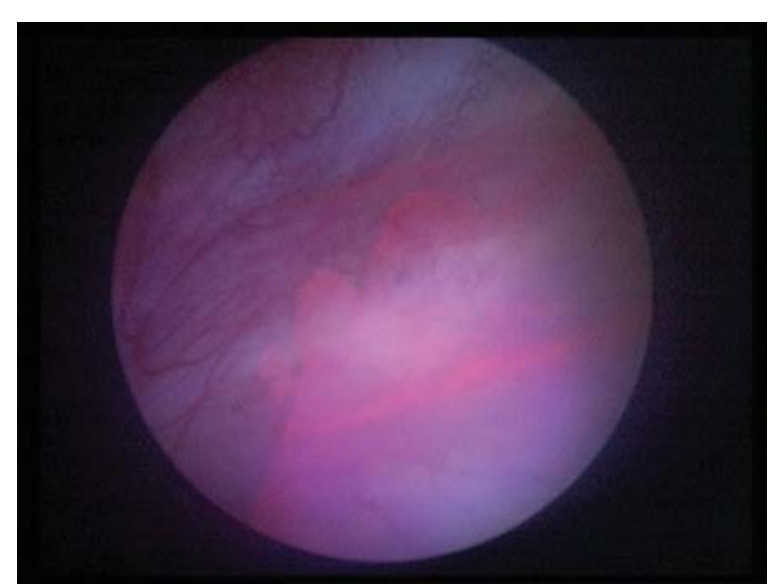

B

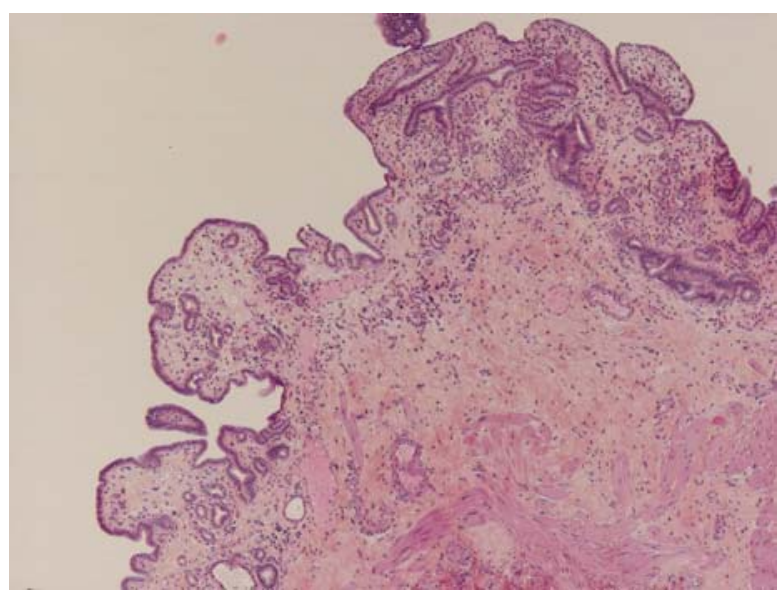

Figure 1. (A and B) FD of NM and histologically corresponding picture of NM with papillomatous, crete like slightly edematous aspects.

A

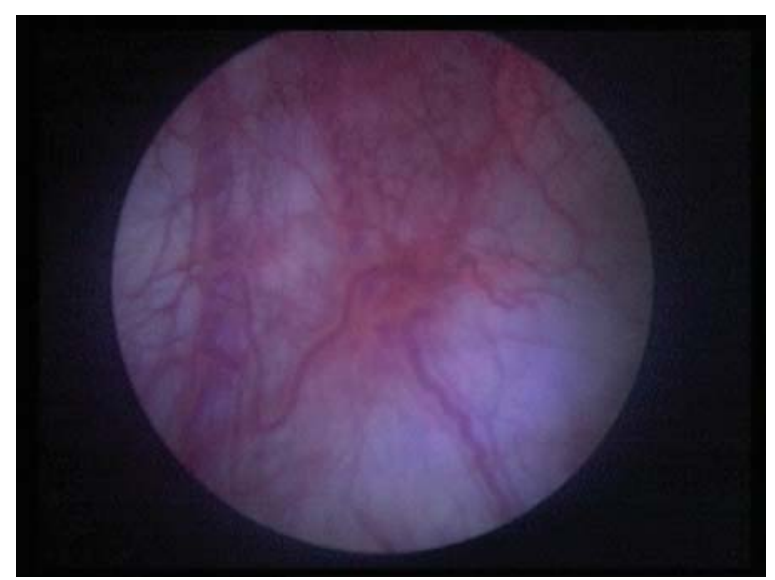

B

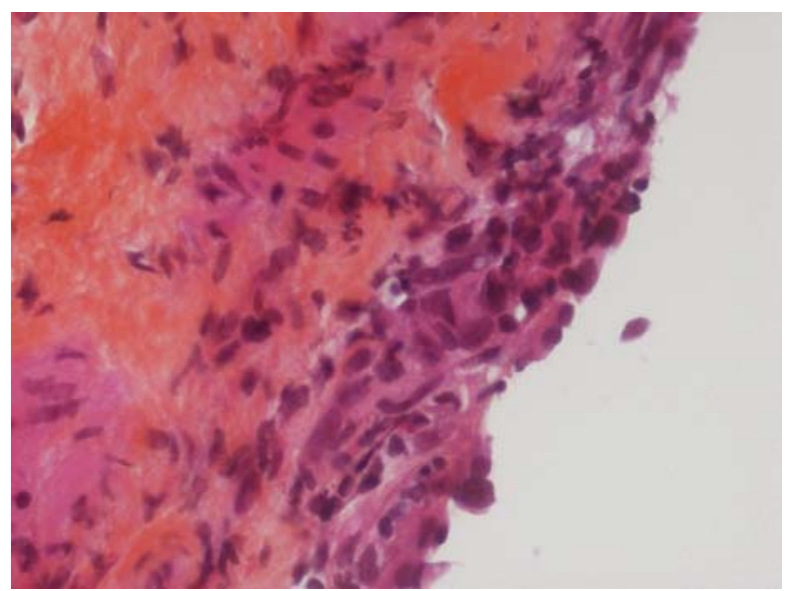

Figure 2. (A and B) Weak fluorescence signals and the histologic aspect with inflammatory urothelium displaying some proeminent nuclei. No more umbrella cells are present, inflammatory cells colonize the urothelium.

A

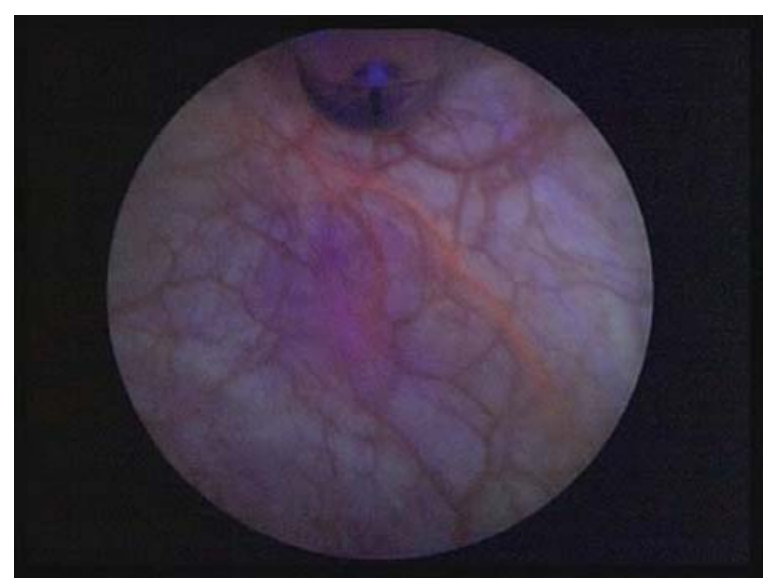

B

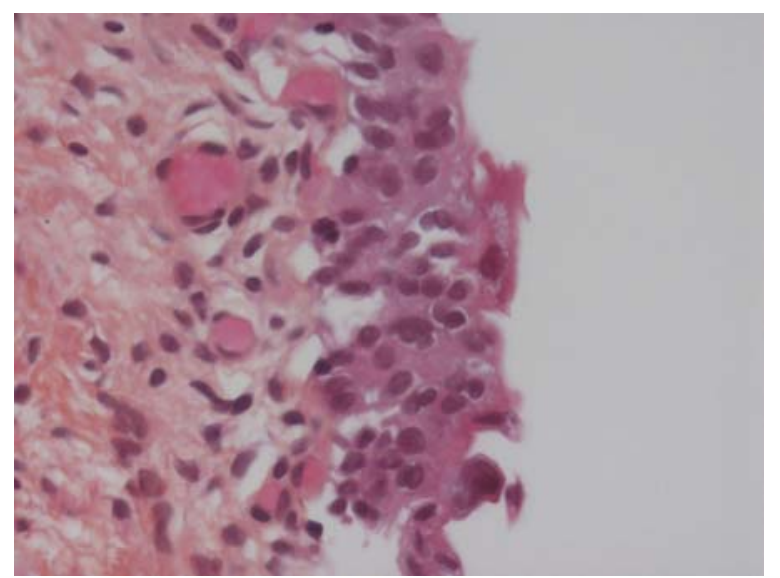

Figure 3. (A and B) LGUH displays sheet-like stronger signals than the previous picture. On the histological slide loss of polarity and enlarged nuclei can be seen. Slight nuclear pleomorphism exists, no inflammation is present.

These data support the hypothesis FUH displays some of the genetic alterations commonly found in bladder cancer. Should positive fluorescent findings of FUH be considered as falsepositive findings or as detection of an early premalignant urothelial lesion with low-risk profile? Several authors have demonstrated in FUH early genetic changes, and FD seems to indicate early but already visible intraurothelial changes (32). 
A

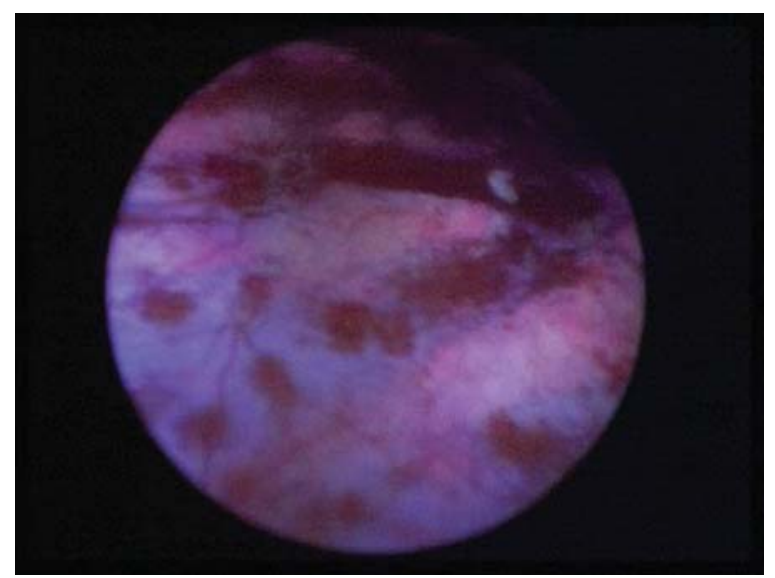

B

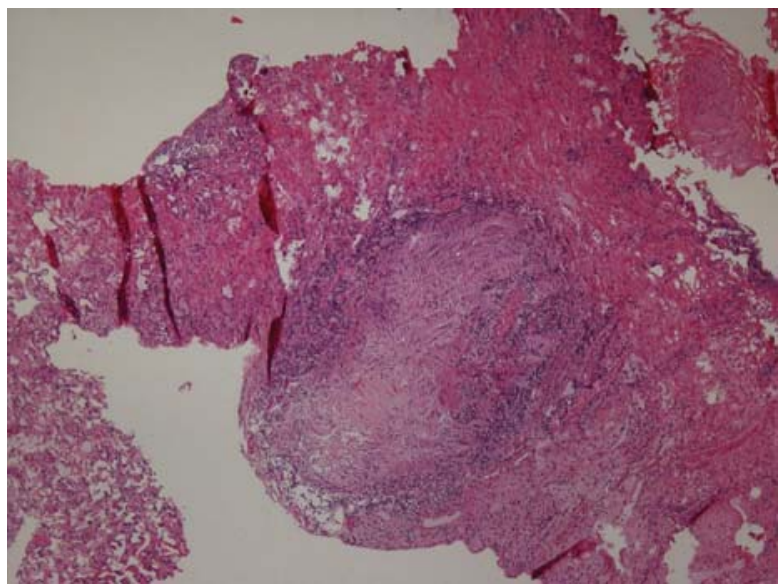

Figure 4. (A and B) Very typical scattered aspect in fluorescence examination of post BCG granulomas. Histologically important granulomas under the lamina propria can be seen, urothelium is not present on this slide.

RA might display a slight reactivity in FD examination, probably linked to inflammation, they represented $45.8 \%$ of the false positive biopsy findings in recent series. We lack recent data to determine, whether $\mathrm{RA}$ is a precancerous lesion and its influence on bladder carcinogenesis (Fig. 2) (13). Previous transurethral resections in patients under surveillance is one of the main causes of false positive findings and can be observed up to 3 months (17).

With the development of FD examination, LGUD that is usually cytoscopically and clinically silent, becomes a diagnostic problem. Therefore, prognosis of isolated LGUD lesions is still a matter of debate as detection rate of LGUD by $\mathrm{FD}$ is $30 \%$ greater than with conventional white light endoscopy $(13,20)$. We consider important to mention LGUD, as LGUD can progress towards Cis and neoplasia (Fig. 3) (24,33). Longer follow-up data are required to show whether it is useful to indicate LGUD in pathologic reports. In FD examination $C$ is is easy to detect and shows a particular, strong and bright light signal. One question remains, whether different subtypes of Cis have different aspects in FD examination. With the increased Hexvix use in urology this problem might be resolved soon.

Granulomas post-BCG therapy can be observed in FD examination, one suggests that the product affects the superficial layer of the submucosa (Fig. 4). The lesions after radiation display atypical fluorescence signals in FD probably linked to inflammation. Many FD aspects still have unknown diagnosis, histology remains the gold standard.

\section{Discussion}

We show that flat lesions correspond to strictly defined criteria and explain some pitfalls in diagnosis of urothelial lesions. Sometimes the frontiers might be fluent and difficult even for experienced pathologist. FD will certainly change the patient management. Several studies have shown an improvement in the diagnosis of bladder carcinoma and $\mathrm{Cis}$ (34). Soloway and Kriegmair tried to resolve this problem already in 1996, considering that dysplasia was not cancer and did not require therapy. Therefore, they suggested not to over-treat patients, who in case of papillary tumor, would have been treated few months later (35). The question of clinical relevance is not resolved in our opinion. Filbeck et al clearly showed in a recent study that FD leads to an improvement in the diagnosis of bladder carcinoma. It allows the early selection of the best treatment option and thus has a potentially positive effect on the prognosis of the affected patients (34). Jocham et al made two sets of records and compared white light cystoscopy and FD. They demonstrated that FD improved treatment in $21.7 \%$ (36). There is evidence that early detection changes patient treatment. Several studies have shown that dysplasia leads to Cis and invasive tumors in $15 \%$ (37). In a recent study Witjes and Douglass (38) suggest that more appropriate treatments might be less aggressive. In the study of Jocham et al (36), two patients had Cis simultaneous to other lesions, which was only detected in FD. Without this information Cis could have been interpreted as treatment failure leading to cystectomy. Several studies have shown that FD transurethral resection reduces residual tumor and recurrence rates and avoid unnecessarily aggressive therapy (34,39-41).

\section{Conclusion}

Several questions remain; we consider that pathologists should try to be as precise as possible in the biopsy or resection report. We think that it is very important to have accurate definitions of flat lesions and with FD experience we will probably change our reports going more into detail. Precise description and schemata are required from urologists to superpose the two experiences, those of urologists, but also those of pathologists, to be aware of problems of the two sides. Short formation courses for pathologists and urologists could be one step forward.

Studies of large patient cohorts are required to validate different ways of bladder cancer treatment and to improve our knowledge of the natural history of bladder cancer and its precursor lesions.

\section{References}

1. Eble JN SG, Epstein JI and Sesterhenn IA: WHO classification of tumors. Tumors of the Genitourinary and Male Genital Organs. IARC Press, Lyon, 2004. 
2. Avritscher EB, Cooksley CD, Grossman HB, Sabichi AL, Hamblin L, Dinney CP, et al: Clinical model of lifetime cost of treating bladder cancer and associated complications. Urology 68: 549-553, 2006

3. Zaak D, Karl A, Stepp H, Tritschler S, Tilki D, Burger M, et al: Fluorescence cystoscopy at bladder cancer: present trials. Urologe A 46: 1519-1527, 2007.

4. Schmidbauer J, Witjes F, Schmeller N, Donat R, Susani M and Marberger M: Improved detection of urothelial carcinoma in situ with hexaminolevulinate fluorescence cystoscopy. J Urol 171:135-138, 2004.

5. Guo CC, Fine SW and Epstein JI: Noninvasive squamous lesions in the urinary bladder: a clinicopathologic analysis of 29 cases. Am J Surg Pathol 30: 883-891, 2006.

6. Sung MT, Lopez-Beltran A, Eble JN, MacLennan GT, Tan PH, Montironi R, et al: Divergent pathway of intestinal metaplasia and cystitis glandularis of the urinary bladder. Mod Pathol 19: 1395-1401, 2006.

7. Morton MJ, Zhang S, Lopez-Beltran A, MacLennan GT, Eble JN, Montironi R, et al: Telomere shortening and chromosomal abnormalities in intestinal metaplasia of the urinary bladder. Clin Cancer Res 13: 6232-6236, 2007.

8. Xiao GQ, Burstein DE, Miller LK and Unger PD: Nephrogenic adenoma: immunohistochemical evaluation for its etiology and differentiation from prostatic adenocarcinoma. Arch Pathol Lab Med 130: 805-810, 2006.

9. Hartmann A, Junker K, Dietmaier W, Schroder S, Lopez D, Hofstadter F, et al: Molecular evidence for progression of nephrogenic metaplasia of the urinary bladder to clear cell adenocarcinoma. Hum Pathol 37: 117-120, 2006.

10. van Oers JM, Adam C, Denzinger S, Stoehr R, Bertz S, Zaak D, et al: Chromosome 9 deletions are more frequent than FGFR3 mutations in flat urothelial hyperplasias of the bladder. Int $\mathrm{J}$ Cancer 119: 1212-1215, 2006.

11. Obermann EC, Junker K, Stoehr R, Dietmaier W, Zaak D, Schubert J, et al: Frequent genetic alterations in flat urothelial hyperplasias and concomitant papillary bladder cancer as detected by CGH, LOH, and FISH analyses. J Pathol 199: 50-57, 2003.

12. Lopez-Beltran A, Cheng L, Andersson L, Brausi M, de Matteis A, Montironi R, et al: Preneoplastic non-papillary lesions and conditions of the urinary bladder: an update based on the Ancona International Consultation. Virchows Arch 440: 3-11, 2002.

13. Hungerhuber E, Stepp H, Kriegmair M, Stief C, Hofstetter A, Hartmann A, et al: Seven years' experience with 5-aminolevulinic acid in detection of transitional cell carcinoma of the bladder. Urology 69: 260-264, 2007.

14. Montironi R, Mazzucchelli R, Scarpelli M, Lopez-Beltran A and Cheng L: Morphological diagnosis of urothelial neoplasms. J Clin Pathol 61: 3-10, 2008.

15. Montironi R, Lopez-Beltran A, Scarpelli M, Mazzucchelli R and Cheng L: Morphological classification and definition of the benign, preneoplastic and non-invasive neoplastic lesions of the urinary bladder. Histopathology (In press)

16. Amin MB and Young RH: Intraepithelial lesions of the urinary bladder with a discussion of the histogenesis of urothelial neoplasia. Semin Diagn Pathol 14: 84-97, 1997.

17. Filbeck T, Roessler W, Knuechel R, Straub M, Kiel HJ and Wieland WF: 5-aminolevulinic acid-induced fluorescence endoscopy applied at secondary transurethral resection after conventional resection of primary superficial bladder tumors. Urology 53: 77-81, 1999.

18. Murphy WM and Soloway MS: Urothelial dysplasia. J Urol 127: 849-854, 1982.

19. Mhawech-Fauceglia P, Cheney RT and Schwaller J: Genetic alterations in urothelial bladder carcinoma: an updated review. Cancer 106: 1205-1216, 2006.

20. Cheng L, Cheville JC, Neumann RM and Bostwick DG: Flat intraepithelial lesions of the urinary bladder. Cancer 88: 625-631, 2000.

21. McKenney JK, Desai S, Cohen C and Amin MB: Discriminatory immunohistochemical staining of urothelial carcinoma in situ and non-neoplastic urothelium: an analysis of cytokeratin 20, p53, and CD44 antigens. Am J Surg Pathol 25: 1074-1078, 2001.
22. Kunju LP, Lee CT, Montie J and Shah RB: Utility of cytokeratin 20 and Ki-67 as markers of urothelial dysplasia. Pathol Int 55: 248-254, 2005.

23. Mallofre C, Castillo M, Morente V and Sole M: Immunohistochemical expression of CK20, p53, and Ki-67 as objective markers of urothelial dysplasia. Mod Pathol 16: 187-191, 2003.

24. Zuk RJ, Rogers HS, Martin JE and Baithun SI: Clinicopathological importance of primary dysplasia of bladder. J Clin Pathol 41: 1277-1280, 1988.

25. Robertson AJ, Beck JS, Burnett RA, Howatson SR, Lee FD, Lessells AM, et al: Observer variability in histopathological reporting of transitional cell carcinoma and epithelial dysplasia in bladders. J Clin Pathol 43: 17-21, 1990.

26. Milord RA, Lecksell K and Epstein JI: An objective morphologic parameter to aid in the diagnosis of flat urothelial carcinoma in situ. Hum Pathol 32: 997-1002, 2001.

27. Tamas EF and Epstein JI: Detection of residual tumor cells in bladder biopsy specimens: pitfalls in the interpretation of cytokeratin stains. Am J Surg Pathol 31: 390-397, 2007.

28. Owens CL and Epstein JI: Significance of denuded urothelium in papillary urothelial lesions. Am J Surg Pathol 31: 298-303, 2007.

29. Ducat D and Zheng Y: Aurora kinases in spindle assembly and chromosome segregation. Exp Cell Res 301: 60-67, 2004.

30. Comperat E, Camparo P, Haus R, Chartier-Kastler E, Radenen B, Richard F, et al: Aurora-A/STK-15 is a predictive factor for recurrent behaviour in non-invasive bladder carcinoma: a study of 128 cases of non-invasive neoplasms. Virchows Arch 450: 419-424, 2007.

31. Grimbergen MC, van Swol CF, Jonges TG, Boon TA and van Moorselaar RJ: Reduced specificity of 5-ALA induced fluorescence in photodynamic diagnosis of transitional cell carcinoma after previous intravesical therapy. Eur Urol 44: 51-56, 2003.

32. Hartmann A, Moser K, Kriegmair M, Hofstetter A, Hofstaedter F and Knuechel R: Frequent genetic alterations in simple urothelial hyperplasias of the bladder in patients with papillary urothelial carcinoma. Am J Pathol 154: 721-727, 1999.

33. Cheng L, Cheville JC, Neumann RM and Bostwick DG: Natural history of urothelial dysplasia of the bladder. Am J Surg Pathol 23: 443-447, 1999.

34. Filbeck T, Pichlmeier U, Knuechel R, Wieland WF and Roessler W: Clinically relevant improvement of recurrence-free survival with 5-aminolevulinic acid induced fluorescence diagnosis in patients with superficial bladder tumors. J Urol 168: 67-71, 2002.

35. Soloway MS, Briggman V, Carpinito GA, Chodak GW, Church PA, Lamm DL, et al: Use of a new tumor marker, urinary NMP22, in the detection of occult or rapidly recurring transitional cell carcinoma of the urinary tract following surgical treatment. J Urol 156: 363-367, 1996.

36. Jocham D, Witjes F, Wagner S, Zeylemaker B, van Moorselaar J, Grimm MO, et al: Improved detection and treatment of bladder cancer using hexaminolevulinate imaging: a prospective, phase III multicenter study. J Urol 174: 862-866, 2005.

37. Hartmann A, Schlake G, Zaak D, Hungerhuber E, Hofstetter A, Hofstaedter F, et al: Occurrence of chromosome 9 and p53 alterations in multifocal dysplasia and carcinoma in situ of human urinary bladder. Cancer Res 62: 809-818, 2002.

38. Witjes JA and Douglass J: The role of hexaminolevulinate fluorescence cystoscopy in bladder cancer. Nat Clin Pract Urol 4: 542-549, 2007

39. Kriegmair M, Zaak D, Rothenberger KH, Rassweiler J, Jocham D, Eisenberger F, et al: Transurethral resection for bladder cancer using 5-aminolevulinic acid induced fluorescence endoscopy versus white light endoscopy. J Urol 168: 475-478, 2002.

40. Fradet Y, Grossman HB, Gomella L, Lerner S, Cookson M, Albala D, et al: A comparison of hexaminolevulinate fluorescence cystoscopy and white light cystoscopy for the detection of carcinoma in situ in patients with bladder cancer: a phase III, multicenter study. J Urol 178: 68-73, 2003.

41. Denzinger S, Burger M, Walter B, Knuechel R, Roessler W, Wieland WF, et al: Clinically relevant reduction in risk of recurrence of superficial bladder cancer using 5-aminolevulinic acid-induced fluorescence diagnosis: 8 -year results of prospective randomized study. Urology 69: 675-679, 2007. 